\title{
ON THE EVALUATIVE CONNOTATIONS OF PHRASEOLOGICAL ZOONYMS IN A CONTRASTIVE PERSPECTIVE (BASED ON FRENCH AND GEORGIAN PHRASEOLOGICAL UNITS)
}

\author{
Natalia Surguladze \\ Department of European Studies \\ Batumi Shota Rustaveli State University \\ 35 Ninoshvili str., Batumi, Georgia, 6010 \\ natalia.surguladze@bsu.edu.ge
}

\begin{abstract}
The article is devoted to the study of French and Georgian phraseological units with animal names/zoonyms that represent emotional attitude of the speaker towards a person or a phenomenon. We decided to study this problem on the basis of phraseological units as phraseology is the sphere which reveals each culture's ethnic and psychological peculiarities, their customs and traditions, reflects their world vision.

The analysis revealed that each culture shows its attitude towards this or that phenomenon emotionally through phraseological units with zoonyms. Such kind of phraseological units intensify emotions and beautify the speech of the speakers. Besides behind each phraseological unit with zoonyms one can see customs, traditions, temperament of different cultures. In order to find similarities or differences between phraseological units of two unrelated languages, we have collected phraseological units with zoonyms and classified them into several groups. Using observational, descriptive, psycholinguistic and contrastive methods, we have found out seven types of zoonyms with evaluative connotations in French and nine types of zoonyms with evaluative connotations in Georgian. It seems that representatives of both cultures use phraseological units with zoonyms to show their emotions. The analysis also revealed that evaluative phraseological units with zoonyms mostly carry negative connotation in both languages.
\end{abstract}

Keywords: zoonyms, emotionality, evaluative, expressiveness, connotation.

DOI: $10.21303 / 2504-5571.2019 .00965$

\section{Introduction}

Deontic modality is an important component of many idioms. Their descriptive component depicts behavior of individs. Deontic modality is one of the main components of idioms, used for describing the person or phenomenon. At the same time, the individ's behavior and his/her personal traits are rationally and emotionally evaluated.

Evaluation is connected with the collection of descriptive features. The character of stereotype is depended on the evaluated object and is found in its meaning. Changes in the word meaning cause the change of the whole stereotype.

Evaluation of the person or a phenomenon is made by a person, who uses subjective and objective factors in the evaluation process.

Charles Bally is truly a creator of modern methods and conceptions of expressive factors of speech. He wrote: "Speech expresses what we think, how our mind works, what our thoughts and ideas are. The object of speech is intellectual sphere of our spiritual life. We express our ideas when we try to evaluate the events objectively. We show our attitude towards the facts (for example: Dieu est bon "God is kind"). We think with ideas which are devoid of expressing subjective emotions (for example: Honère ton père et ta mère - "Honour thy father and thy mother") [1].

One of the peculiarities of evaluation is that there is subjective factor in it and it is mixed with objective one. It does not matter the expression directly shows the evaluated object or not, it reflects an attitude between subject and object. Behind every expression there is an individual or society who evaluates the object. According to A. Ivin: "in every expression one may find connection between the subject (s) and the evaluated object" [2]. V. Vasilenko believes that evaluator is always a person, a specific individual, or the whole society [3].

The frame of evaluative modality comprises explicit (object of evaluation) and implicit elements (aesthetic object of evaluation - beautiful-ugly). 
Emotional modality is based on the world vision of the speaker and it is just what makes the idiom more expressive. Semantic structure of idioms expressing behavior is much more difficult to investigate. Here deontic modality is depended on rational evaluation, showing the relevance of X's behavior to the norms of a specific society. It is expressed with axiological predicates: Good / bad. Deontic and axiological modalities make a great impact on the listeners. As for emotional modality, it gives rise to the emotions and a specific image is born in the mind of listeners.

The analysis of Georgian and French idioms denoting behaviour revealed that the number of evaluative speech acts in Georgian prevails its French counterparts. It is doubtless that we deal with evaluative speech act, effected by illocutionary force. Listeners' emotional state changes every time when the speech action changes and causes the perlocutionary effect of an evaluative speech act. Besides, a reaction on expressives results from one's emotional state. In other words, evaluative expressions like idioms denoting behavior, can be considered as a type of illocutionary act.

Evaluative scale is a complex structure. It contains a number of features that can independently move forward and backward. Just this is the subjective / emotional aspect of evaluation. Descriptive features of the object are depended on the above mentioned features.

An evaluative scale is dynamic and goes either forward or backward. There is a symmetrical axis between the semantic opposition ,good-bad“, where the increase of one feature means the dicrease of the other [4].

Some scholars believe that there are certain stereotypes concerning features of the objects. For example "sweetness" is one of the features of the object, which is defined by Leibnich as "having the taste of sugar". Such kind of stereotypes are found in idiomatic expressions like "as white as snow", "as yellow as a lemon", "as long as a bar". An evaluative scale can gather the features so that it can fully coincide with stereotypes [5].

Person's normative language is found in the semantics of zoonyms. They reflect subject's negative features. Normative indications that are implicitly expressed in idioms have no variants. They have the generelised nature and are directed towards the representatives of this or that culture.

Thus, the aim of the research is to study French and Georgian phraseological units with animal names/zoonyms that represent an emotional attitude of the speaker towards a person or a phenomenon. At the same time, we aim at making their semantic and thematic classification and finding similarities and differences between the world visions of two different cultures. A contrastive analysis of two unrelated languages is always interesting as they reflect national mentality of each culture.

\section{Theoretical Background}

The most natural way of studying semantics of phraseological units with evaluative components, is studying the emotions, caused by them. These emotions have a form of extensional which combines a range of interconnected variables, including a subject, object, location, time, social roles of subject and object (if the object is a person ) etc.

The word ,extensional“ means a set of relevant features or parameters that creates a typical situation in the world and makes its reflection in our consciousness. The hypothesis, which is created on the basis of frame theory, is our starting point. This theory implies that knowledge about the universe is formed on the basis of certain norms and rules and the knowledge gained is a combination of stereotypical situations.

When we define extensional of the word „Hatred“, we use its universal-typological description. Thus, "Hatred" is a human emotion, an extremely strong feeling of dislike which is directed against certain individuals, groups of people, objects, behaviours, concepts and ideas.

More precisely, "Hatred" is a sense, the object of which is mainly a person (rarely a group of individuals or a social groups). It is a stable, intense, negative emotion, which is caused by abolishing moral or ethical norms of one person by another person in the process of interpersonal communication, or by the person who feels his/her superiority over another person, belonging to a less prestigious society. In the first case, the subject and object of evaluation can be the same person [6].

The person who shows hatred towards the other person, has some kind of imagination that he/she stands morally, ethically or socially higher than the other one, thus, the hater tries to deval- 
uate the victim. The hater may see the object of the hatred as bad, immoral, dangerous, or all of this together. The word „Hatred“ is associated with a great variety of emotions: irritation, cruelty, indignation, fury, rage, etc.

Extensional of „Hatred“ can be described in this way: X evaluetes $\mathrm{Y}$ in a negative way and shows an extreme dislike towards Y not only in behaviour, but in speech as well. X's emotional attitude is based on his/her idiology or imagination - he/she (the hater) is better than Y (the object of the hatred).

"Hatred" is an emotion, an attitude that may have either ethical or social basis. Both forms of "Hatred" characterise not only the hater but the object of the hatred. Ethical hatred is based on person's moral-ethical attitudes and is characterised by the stable character. As for the Social hatred, it is seen in the society in the ralation between the members of the society. Both types of hatred are of great importance and are connected on the one hand with social status meaning, on the other hand with moral-ethical meaning.

Extensional 1 (Ethical Hatred). Ethical hatred reflects an emotional attitude of the hater towards the object of hatred. The object of hatred is always a person, even in the cases when the hatred is directed to a social group.

Cowardice, impatience, deception, hypocracy are basic manifestations of human being's weaknesses and deserve hatred. Feelings mentioned above are considered as betrayal towards oneself.

Psychologists who study social behaviour of human beings, note that people's behaviour towards other human beings or other peoples' behaviour towards them, or even the people's behaviour towards themselves is based on one and the same rule. In many cases people see their negative sides themselves and are ashamed of their behaviour [7]. The same can be said about the person's emotional attitude towards him/herself. In relation with other people, a person formulates some kind of feeling towards him/herself. A person has both - personal (emotional attitute towards oneself) and social (emotional attitude towards members of society) feelings.

Extensional 2 (Social Hatred). The object of social hatred is a person, belonging to a certain society (linguistic, racial, social-administrative, professional). He/she believes that the social status he/ she has or social group he/she belongs to is more prestigious than the one, the object of hatred belongs to.

Accordingly, the basis of social hatred is Y's absence of social choice. In other words, hatred arises because of an assymetric condition in relation [8].

In the case of social hatred when the hatred is shown towards someone's profession, $\mathrm{X}$ and $\mathrm{Y}$ belong to different social groups and therefore have different professions - profession of the object of hatred is inferior than the profession of the hater [8].

Hatred is a strong and complex feeling, which comprises different components:

a) role - X's pride and disrespect towards $Y$;

b) rational, critical judgement;

c) devaluation of Y's importance;

d) emotion that varies greatly, according to the situation: irritation - offence - anger - resentment - fury - rage; One of the components mentioned above may become illocutionary force of an expression.

Ignoration/Rejection/Neglection is an emotion, the object of which might be either a person, a social group, animite or inanimate things. It is less intensive than the feeling of hatred. Ignoration is not directed to a subject but is seen in one's behavior and speech. It is connected with presonal and social norms.

Extensional of ignoration can be represented thus: $\mathrm{X}$ feels ignoration towards the object $(\mathrm{Y})$ and expresses this feling in his behaviour or speech. $\mathrm{X}$ believes that $\mathrm{Y}$ is of no value, is not interesting at all, and he/she should not pay attention to him/her or contact with him/her.

Ignoration is the emotion, having similarities with hatred and humiliation. Ignoration resembles hatred when the emotion increases and reaches its highest point. At the same time it resembles humiliation, as they contain common seme.

Extensional 3 (ignoration of a thing). It can be represented in this way: $\mathrm{X}$ believes that $\mathrm{Y}$ can not meet X's demands. Y is invaluable in X's eye. Y might be any type of object: animate or inanimate things - somatism, artifact (artificial), locative, etc. 
Ignoration of the thing happens when $\mathrm{X}$ sees that $\mathrm{Y}$ does not possess enough quality. In this case ignoration of a thing becomes closer to the feeling of humiliation. X evaluates Y's appearance and judges its aesthetic value. The number of lexemes expressing extensional are many - some of them are metaphorical, others are suffixal derivatives.

Extensional of humiliation can be represented in the following way: $\mathrm{X}$ believes that $\mathrm{Z}$ does not coincide with the norms $(\mathrm{N})$ of X's world vision, which is standard for X. The object causes negative emotions (R), $\mathrm{X}$ intentionally tries to reduce $\mathrm{Z}$ ' s importance.

Main features of humiliation that differentiate it from hatred and ignorationare: a) relevant qualities of an object are inaccessible with its standard form; b) intention to humiliate the object, restrict its importance; Humiliation is different from ignoration as the object has no importance for X. In Hatred we can't notice intention of X to humiliate Y.

Extensional 4 (Degradation of an object/a thing) This type differs from humiliation of a person. Humiliation of a person has much in common with ethic hatred and personal ignoration [8]. Extensional 4 is close to hatred as $\mathrm{X}$ believes that he/she is superior than the object of the hatred. Humiliation does not mean X's proud behaviour towards Y. X's intention is to humiliate the latter and reveal its imperfection in teleological or aesthetic aspects [9]. The result of humiliation is resentment from Y's side. X aknowledges his/her priority over Y and shows arrogance towards $\mathrm{Y}$. When humiliating, $\mathrm{X}$ purposely humiliates $\mathrm{Y}$, but in the case of hatred and ignoration/rejection both $-\mathrm{X}$ and $\mathrm{Y}$ have their specific roles. Thus, there is no intention from X's side to humiliate $\mathrm{Y}$. This is the case when humiliation is related to cursing and swearing (bad language).

Humiliation and ignoration have different mental syntax. $\mathrm{X}$ wishes to disapprove/ reject $\mathrm{Y}$ in the case of humiliation, but in the case of hatred, $\mathrm{X}$ wishes to reject $\mathrm{Y}$ because it is inferior and can't reach the standard.

Disapproval is a negative emotion, expressed rationally by the speaker. The demage from it is less intensive. Below are the examples of disapproval that vary in intensity.

On the one hand, disapproval exists in the unison of emotions: hatred, ignoration, humiliation. On the other hand, it exists indipendently. Condemnation is a specific form of the latter. Disapproval arises, when $\mathrm{X}$ starts to believe he/she possesses the norms of behaviour, which are violated by Y intentionally. X considers Y's behaviour wrong and even criminalistic. Y intentionally breaks social norms of behaviour, but $\mathrm{X}$ appears to be strict defender of the norms and acts like a moralist. If $\mathrm{X}$ is a friend of $\mathrm{Y}$, in the process of disapproval he/she gets rid of a friend, stands aside and plays a role of a strict lawyer. $\mathrm{Y}$ is guilty, he/she breaks the rules, regulations or traditions.

Variant 1. X believes that Y's behaviour is wrong and unacceptable for the society they live in. Y's behaviour does not coinside with X's norms and therefore the norms of the society. $\mathrm{Y}$ commits crime breaking the rules of the society.

Variant 2. X believes that $\mathrm{Y}$ breaks universally established rules in the process of interpersonal communication and social behaviour.

Features of a person's behaviour are evaluated in different ways. In many cases it is depended on X's mood and the criteria, he/she uses in the process of evaluation of Y. If the feature is evaluated from the position of ethics, we will have the case of hatred.

Extensional of critisism or disapproval vary and can be represented in the following way: $\mathrm{X}$ believes, Y made a mistake and failed. But Y made a mistake involuntarily, unconsciously, having no idea what he/she was doing; $\mathrm{X}$ not only underlines the fact of making a mistake, but tries to explain Y what was wrong in his/her behaviour. Thus, $\mathrm{X}$ tries to make Y understand his/her fault. In this case $\mathrm{X}$ is a mentor, a good adviser, an experienced friend who tries to teach $\mathrm{Y}$. He/she is not a strict laywer judging Y. Y is a person (a child, a foreigner, a drunkard, an invalid, an old man) who knows no rules of behaviour. This is the main reason of breaking the rules. Y breaks the rules unconsciously and $\mathrm{X}$ is tolerant towards him/her. Such kind of critisism resembles reproach.

Critisism / disapproval is different from judgement. It is less severe. The subject is not againt the object and is patient and merciful towards the object's faults. People behave in this way, when the person critisized is dear for them. That is why they do not critisize them so strictly and try to explain what was their fault. 
Thus, there are two ways of expressing disapproval. The first one is the combination of emotions (disapproval - in its broad sense), while the other one can take the form of critisism and disapproval (variants of rejection).

It is really difficult to study semantics of basic emotions. The problem is not in the number of components, but in the extensional. Variables (X, Y, Q, W, N) make up the extensional of a certain emotion, get reference which is depended on speaker's background, on his/her social and moralistic mood, on the social norms and even on Y's characteristic features. Y has the abilty of causing emotions of different intensity [6].

\section{Evaluative connotations of phraseological units with zoonyms in French}

Hatred

1. Faire le chien couchant (aux pieds de qn) - flattery.

2. Jeter le chat aux jambes de qn -cheating, faking out.

3. Manger la grenouille-embezzlement.

4. Caquet bon bec - venomous speech.

5. La patte d'araignée -face to face flattery.

6. Jeter un os à la gueule d'un chien pour le faire taire - bribery.

7. Vouloir la peau de qn - wishing someone's death.

8. Avoir un courage de loup -showing bravery towards the weak.

9. Vendre la poule au renard - betrayal, treachery.

10. Peureux comme un lièvre - coward [10].

\section{Ignoration/ Rejection}

1. Faire le hibou - behave like an owl.

2. Courir comme un chat maigre - to be a womanizer.

3. Glorieux comme un paon - proud.

4. Bête comme un âne (comme une carpe, un dindon, une grenouille, une oie, hareng saur) crazy, mad.

5. Chat coiffé - a very ugly person.

6. Chien de cour-class master, head teacher.

7. Coiffure à la chienne - forelock.

8. Sacré chien - choking vodka [10].

Critisism/disapproval

1. Bayer aux mouches - doing nothing, being idle.

2. Faire sa panthère - wandering.

3. Le chien du jardinier - mean, stingy.

4. Gobeurs de mouche - a time waster.

5. Agir en renard - sly behaviour.

6. N'avoir (de) la gueule - ostentation.

7. Ingrat comme les chats - ungrateful, ungracious.

8. Se servir de la patte du chat pour tirer les marrons du feu-achieve success with the help of others [10].

Mockery

1. Geai paré des plumes du paon - the bird in borrowed feathers.

2. Brave comme un lapin - (as brave as a rabbit) - coward.

3. Écriture de chat - scribbled.

4. Contes de Peau d'âne - invented stories.

5. Avoir la légèreté d'un ours - as clumsy as a bear.

6. Être aussi chanceux que le chien à Brusquet - an incredibly lucky person ( a lucky dog)

7. Être comme un éléphant dans un magasin de porcelaine - an elephant in a porcelain store (like a bull in a china shop).

8. Taquiner les dents d' éléphant - (mocking at elephant's tusks) playng the piano badly.

9. Aller comme une bague à un chat - (like a cat with a ring) something that does not look nice [10]. 


\section{Hatred/ Mockery}

1. Gueule à caler les roues de corbillard - an ugly person.

2. Propre comme une écuelle à chat - (clean like a cat's bowl) (dirty as a pig - Georgian), filthy, dirty.

3. Peau de vache - (the skin of a cow) - impudent, shameless.

4. Une vieille peau - (old skin) - old bitch.

5. Peau de balle - (leather of the ball) - to be penniless [10].

\section{Ignoration}

1. Être fait comme un meneur d'ours - (dressed as a leader of bears) - dressed dirtily

2. Cheval de bat - ( pack horse) stupid, yokel.

3. Enculeur de mouches - nitpicker, faultfinder [11].

Irony

1. Médecin de cheval - drastic medicine, bitter medicine [11].

\section{Evaluative connotations of phraseological units with zoonyms in Georgian}

A person's perception of the world is the part of common „Picture of the World,“ but it has the itspersonal character and is expressed in different ways - verbally or non- verbally (with gestures, mimics, intonation). Linguistic units of every language have the ability expressing different emotions and attitudes towards human beings, objects, phenomena. Expressive lexical units, or expressives make up a fund of expressive means.

The content of expressive units, or expressive effect, as V. Telia calls it, is created on the basis of denotative-conotative semes, but not every denotative seme is able to create expressive lexical units. Expressive lexical units are mainly created by those denotative semes that express some features of human beings or phenomena. In other words, lexical units should express amount, intensity, strength, quantity, quality or some other features, peculiar to the person or phenomenon described. Expressive lexical units should possess elements of normative-social appraisal - collective or personal (positive-negative; tasty-disgusting; aromatic-malodorous, useful-useless, valuable-invaluable, moral-immoral; kind-evil; clever-silly; deep-superficial). We may call such kind of lexemes expressives [5].

Expressives can be directed to the speaker: "Ra dzaglis fekhi shevchame!" (directly "I have eaten a dog's leg"). Figuratively the phraseological unit is used in reference to a person who walks all day long like a dog, wants to find some food but returns home empty-handed; "zhaglis kefa ar mesmis!" (directly: "I can't hear dog's barking"; figuratively "I am so hungy that I can't hear dog's barking; ,vis ra gveli shevutsvi?” (Did I feed you with a roast snake?) or “vis ra viri movpare?”(Did I steal your donkey?) figuratively - "Did I make you angry with my behaviour?"; "dzagls vachmev chems khorts!" ("I will make so that a dog eats me up") figuratively - "I will tolerate all, but I will do my best to succeed"; "mahmadis mtredivit kurshi chamdzakhis" (utters one and the same sound like a pigeon) - figuratively „makes me do something”; "Datvs chemtvis araferi sheuchamia” (“A bear has not eaten my food or possessions") figuratively - "A bear is not the reason of my poverty"; "mglis kochs davtsvav!" (I will burn a wolf's malleolus) - the phraseologism is used when somebody finds the stolen goods and immediately becomes an enemy of a thief. The phrase is used as a threat in Georgian. "me var da chemi tskheni!" ("Me and my horse!") - figuratively "I need no one, except my horse', "mkvdari viri khom ar migikidnia, rom nalebi ahkaro?" ("Have you sold a dead donkey to him?) - figuratively "Does he owe you money?" [12]

Expressives can be directed to the addressee: "rkebiamogivida?" (directly: "Do you have horns on the head?" Figuratively - "What did you get from it?). This phraseologism is used in reference to an impatient person who tries to get something faster than others. "khvlikebis jogi ar damifrtkho!" (directly "You can’t frighten my lizards!" figuratively - "You can’t frighten me!"); “tsofianma dzaglma khom ar dagglija?" (directly - "Did a mad dog tear you into pieces?", figuratively - "Why are you so infuriated?"); “mousvi bakakuri!” (figuratively: "Get rid of me!"); “mtskerebiki nu aafrine!” (directly: "Do not fly the quails away!” Figuratively - "Do not be silly!”) [12].

Expressives contain elements of appraisal. They possess special referential features and have the function of predicate. Semantically judging, expressives are metaphorical and are directed 
towards addressee. "she ofofo, shena!" (directly: "You hoopoe! Figuratively" "You dirty and smelly one!"); "najogari kharia!" ("He looks like a bull" figuratively - "He is fat"), "metsamete gochia!" (directly: "she is thirteenth piglet" figuratively - she is coquette!); "gazafkhulis mertskhali”(,spring swallow!" - is said about a person who brings good news) [12].

Appraisal determines illocutionary goals of a speech act, confirms its feature $<<+>>$ or $<<->>$ and increases its expressiveness. In Georgian phraseological units there is a great variety of idioms, expressing different emotions: mockery, hatred, threat, cursing and swearing, etc.

Mokery: "eg nakazmi zogi shens tsitsilebsats daukare!" (directly: "Throw it to your chicks!" figuratively: "You can’t cheat me!"); “jors nalebi ar amikaro!” (figuratively: "You can’t take away anything from me!"); "shen imis dzaglasats ver aakefeb!" (directly: "You can’t make his dog bark!" figuratively: "You won't be able to attract his attention"); "rka-dekeulebi ar gamomireko bakidan!" (directly: "You can't move my horned cattle from the barn" figuratively: "You can't beat / harm me!"); "chiti fafas vaketeb!" (directly: "I am cooking porridge” figuratively: "It is clear what I am doing!”), "kvavebi shavs chaitsvamen!” (directly: “crows will wear black”, figuratively: "Noone will be disappointed by his/her unhappiness or failure"); "madlis tkavs vin tsamogaskhams shvilosa!" (directly: "Who will cover your body with wonderful skin?" figuratively: "No matter how hard you try, noone will thank you for it") [12].

Hatred: "ra piri gikars ofofivita" (directly: "Your mouth smells as awful as a mouth of a hoopoe", figuratively: "You use bad language!"); "ai dzaglits gsenebaze!" (directly: "here is a dog!"). This idiom is used in the case of seeing a wicked man. "Mglis tvalze naxva (vinmesi)" (directly "look at someone with wolf's eye", figuratively: "dislike someone from the first sight") [12].

Threat: "ise gagikhdi saqmes, rom shens gulze dzagli davapuro" (directly: "I will do so, that a dog will be fed on your chest" figuratively: "I will disgrace you!"); "mumlits nu daajdeba" (directly: "Do not let sandflies sit on it" - figuratively: "Do not harm him/her!"); "zatsashi frinveli ver gadaifrens, zirs chainchvela ver gaivlis chemi shishit" (directly: "No fly can fly in the sky and no ant can move on the land" figuratively: "I am a threat to all creatures, everyone is afraid of me!" [12]

Cursing and swearing: "mglis mutselshi gasadzvreno", "datvis samzhaved gasakhdomo", "datvis shesachmelo". When a bear catches another animal, it burries it underground, where it is softened and soured. In Khevsureti (one of the regions of Georgia) people curse in this way: "ai shen datvis samzhaveo!" (Directly "You the soured portion of a bear!", figuratively "Let a bear eats you up!"); dzagli da kata daakvda mavanso! (a dog and a cat were considered as impure animals, noone used their flesh and noone sacrificed them). This type of cursing "dzagli da kata daakvda mavanos" (saflavze) is heard when somebody wants to curse the dead person [12].

Sneering: "buzsats ver amifren!" (Direct meaning: "You can’t fly a fly in front of my face", figuratively: "You can’t harm me!"); "kverna daichira!" (directly: "He has caught a marten", figuratively "He was beated; He failed;"); "ver mogartvi gochis/ghoris tavi" or "ver mogartvi boloki da khbos tavi" (directly: "I can not serve you with the head of a piglet/pig or a radish and a head of a calf", figuratively "You can not make profit from it"[7].

Ignoration: "chian tkemladats ar vagdeb!" (directly: "He is like a wormy plum" figuratively: "He is of no value"); "machvis fekho!" (directly "You are a typical badger!" figuratively "You are mankin!"); "katis natrevi" (figuratively - an ugly person); "saghore” (directly "a pigpen", figuratively "a dirty/filthy place or flat" [12].

Sympathy towards someone or something: "mglisa da kornis lukma" (directly "the portion of a wolf and araven", figuratively "a worthless person”); "tskhvari fekhze hkavs gamobmuli”(directly "a lamb is tied to her/his leg" figuratively "he/she is old and is going to die soon"); "kata moukvdeba khelshi” (directly: "a cat will die in his/her hand" figuratively "he/she is very poor"). It is known that a cat eats the least of all domestic animals and if a person can't feed a cat, he /she is really poor [12].

Critisism: "madli matlad gadamiqtsia" (directly "He turned my kindness into larva", figuratively "he/she did not see my kindness", "he behaved ungratefully" [12].

Reproach: Phraseological unit "sami dghis khbo tskalze chava da shen ragha dagemarta?"(directly: "Even a three day old calf can go down the river and drink water") is used in reference to a lazy person who leads an idle life [12]. 


\section{Results and Discussion}

The analysis of the theoretical and practical material revealed that evaluation is connected with the unity of descriptive features. The type of stereotype is depended on the object evaluated and finds its materialisation in its semantics. The change of denotatum may cause the structural change of a stereotype.

One of the main peculiarities of evaluation is that there is a subjective factor in it. More than that, subjective and objective factors are interconnected. Evaluator is a human being.

Deontic norm is connected with the norms of individ's behavior and social rules which are essential for the functioning of society. These norms find the place in individ's consciousness and form the regulations for behavior. Moralistic norms regulate psychic activity. They may regulate not only physical but psychic activity.

After studing semantic peculiarities of animalistic somatisms and zoonyms, expressing behavior, we found out their place on the evaluative scale.

\section{Conclusion}

1. Conducted the contrastive analysis of phraseological units with animal names (total number of phraseological units in both languages - 80), we have found out seven types of zoonyms with evaluative connotations in French and nine types of zoonyms with evaluative connotations in Georgian. In French language, zoonyms are connected with the following concepts: Hatred, Ignoration/ Rejection, Critisism/ disapproval, Mockery, Hatred/ Mockery, Ignoration, Irony. As for Georgian, there we have found more concepts, connected with zoonyms with evaluative connotations. They are Mokery, Hatred, Threat, Cursing and swearing, Sneering, Ignoration, Sympathy towards someone or something, Critisism, Reproach.

2. The analysis revealed that evaluative phraseological units with zoonyms mostly carry a negative connotation in both languages. It should be mentioned, that phraseological units with zoomyms, having a negative connotation, is $14 \%$, in Georgian $-12,8 \%$. As for the phraseological units with zoonyms with positive connotations, their percentage in French is $5,4 \%$ and in Georgian $-4,8 \%$.

\section{References}

[1] Bally, Ch. (1961). French Stylistics. Moscow: Izdatelstvo inostrannoi literatury, 394.

[2] Ivin, A. (1970). Basis of Evaluative Logic. Moscow, 230.

[3] Vasilenko, V. (1966). Value and Evaluation. Problem of evaluation in Philosophy. Moscow, 5.

[4] Arutunova, N. (1983). Russian Sentence. Structure and meaning. Moscow, 322-333.

[5] Wolf, E. (1985). Functional Semantics of Evaluation. Moscow: Nauka, 246.

[6] Shakhnazarovich, A., Graphova, T. (1991). Semantic Structure of Emotional Predicates. Linguistic Mechanisms of Expressiveness. Moscow, 67-68, 90-98.

[7] Shibutani, T. (1969). Social Psychology. Moscow: Publishing House "Progress", 534.

[8] Krisin, L., Shmelev, D. (Eds.) (1976). Social- linguistic Investigations. Moscow: Publishing House "Nauka", 232.

[9] Ostin, J. (1962). When Actions are Words. New in Foreign Linguistics. Seriia «Teoriia rechevykh aktov», 17, $22-131$.

[10] Phraseologisms with zoonyms and aminalistic somatisms in French and Georgian (2009). Batumi: Batumi University Press, $76-85$.

[11] Bibileishvili, Ts., Darashvili, L., Gachava, R. (2010). French-Georgian Phraseological Dictionary. Tbilisi: Publishing House „Diogene.“

[12] Sakhokia, T. (1955). Qartuli Khatovani sityva-tkmani (Georgian Figurative Expressions-in Georgian). Tbilisi: Publishing House „Merani“. 